\title{
ANÁLISE DO PROCESSO DE CERTIFICAÇÃO ISO 9001 EM UMA EMPRESA DA CONSTRUÇÃO CIVIL EM FRUTAL - MG
}

\author{
SILVA, Adriana Cristina ${ }^{1}$ \\ SOUZA, Iracema Caproni de ${ }^{2}$ \\ LIMA, Aida Franco de ${ }^{3}$ \\ PINHEIRO, Hyses de Cássia Queiroz ${ }^{4}$
}

\section{doi 10.33726/akdpapers2447-7656v8a52019p130-152}

RESUMO: No mercado atual, devido à concorrência acirrada, torna-se imprescindível possuir práticas de gestão voltadas à qualidade de produtos e serviços prestados por organizações. Assim, é importante compreender de modo mais aprofundado a ISO 9001 , conjunto de normas que servem como modelo a ser aplicado no sistema de gestão das empresas, para a obtenção da certificação de qualidade. Por método, adotamos o este estudo de caso, no que se relatam os benefícios e as dificuldades da implementação e manutenção do Sistema de Gestão da Qualidade ISO 9001 em uma empresa do setor da construção civil numa cidade média de Minas Gerais. A análise foi obtida com base na coleta de dados com os funcionários e com a coordenadora da qualidade, que foi a responsável pelo gerenciamento da norma na empresa. Os resultados demonstram que a qualidade é essencial para o sistema de uma organização, devendo ser desenvolvida a fim de se aumentar o sucesso da corporação.

PALAVRAS-CHAVE: Sistema de Gestão da Qualidade, ISO 9001, Setor da Construção Civil

ABSTRACT: In today's market, due to fierce competition, it is essential to have management practices focused on the quality of products and services provided by organizations. Therefore, it is important to understand ISO 9001, a set of standards that serve as a model to be applied in the company's management system, in order to obtain quality certification. By method, we adopted this case study, in which we report the benefits and difficulties of implementing and maintaining the ISO 9001 Quality Management System in a construction company in an average city of Minas Gerais. The analysis was obtained based on data collection with employees and the quality coordinator, who was responsible for managing the standard in the company. The results demonstrate that quality is essential to an organization's system and should be developed to increase corporate success.

KEYWORDS: Quality Management System, ISO 9001, construction sector

\footnotetext{
${ }^{1}$ Mestre em Sustentabilidade Socioeconômica Ambiental (UFOP). Docente da UEMG - Unidade Frutal, lotada no Depto. de Ciências Sociais Aplicadas. Coordenadora da Qualidade/RD, na Construtora Bom Teto Ltda. Contato: adrianacriss@gmail.com

${ }^{2}$ Mestre em Geografia (UFU). Docente da UEMG - Unidade Frutal, lotada no Depto. de Ciências Sociais Aplicadas. Contato: iracema.caproni@uemg.br

${ }^{3}$ Doutora em Comunicação e Semiótica. Docente da UNEMAT, Campus de Alto Araguaia. Contato: aidafrancodelima@gmail.com

${ }^{4}$ Especialista em Gestão Pública Municipal pela UEMG - Universidade do Estado de Minas Gerais. Contato: hyses_queiroz@hotmail.com
} 


\section{INTRODUÇÃO}

O presente trabalho tem por finalidade analisar a implantação da certificação da qualidade ISO 9001 (International Organization for Standardization) e PBQP-H ${ }^{5}$ (certificação exigida pela Caixa Econômica - e demais instituições financeiras - para ter acesso a financiamento construtivo) em uma empresa do ramo da construção civil localizada na cidade de Frutal - MG, e, desse modo, identificar os resultados positivos, as dificuldades e relatar os mecanismos para a manutenção dos benefícios e da melhoria continuada do sistema de gestão da qualidade.

Abona um estudo como este, o fato de que uma empresa seja certificada, é necessário que se sigam critérios internacionais e padronizações nos serviços prestados, assegurando-se, um elevado nível no atendimento aos clientes, superestimando a sua satisfação.

Justifica-se ainda nossa pesquisa, por um lado, a condição de que o ambiente organizacional, tanto interno quanto externo, continuamente passa por mudanças que interferem diretamente nas empresas. Por outro lado, os consumidores estão cada vez mais exigentes, fazendo com que as empresas se sintam obrigadas a se adaptar às exigências deles.

Logo, se estas últimas circunstâncias são ignoradas, isso pode derivar até mesmo na saída da empresa em questão do mercado. Logo, implantar e desenvolver sistemas de gestão da qualidade, ferramentas tecnológicas, processos gerenciais, dentre outros mecanismos, resultarão em vantagens competitivas para a empresa.

Para Mello et al. (2009), o crescimento da globalização fez com que a gestão da qualidade se tornasse imprescindível para as empresas, tanto na melhoria continuada quanto para a liderança de mercado. Assim, ao se implementar numa organização um sistema de gestão da qualidade, os benefícios alcançarão não só os limites internos, mas também os externos, atingindo-se clientes, fornecedores, acionistas, colaboradores e a sociedade no entorno como um todo.

A temática desta investigação, portanto, interessa tanto à comunidade acadêmica quanto à empresarial, a qual procura conhecer o processo de implantação da ISO 9001 e os resultados positivos e negativos em cada etapa. Além disso, despertar uma reflexão de

\footnotetext{
${ }^{5}$ Programa Brasileiro da Qualidade e Produtividade Habitacional.
} 
como a certificação contribui para o aprimoramento dos envolvidos e das organizações é objeto adjacente desta proposta.

É neste contexto, por exemplo, que Marshall Junior et al. (2010) afirmam que os administradores de empresas de qualquer tamanho ou ramo de atuação têm consciência de que não se pode negar a importância da implementação e do desenvolvimento de estratégias organizacionais, a exemplo de sistemas de gestão da qualidade, para que se alcancem a excelência e a eficácia do desempenho organizacional.

O comprometimento pelo setor da construção civil ocorreu a partir de dados informados pelo Sindicato da Indústria da Construção Civil do Estado de Minas Gerais (SINDUSCON - MG), que previu a estagnação do setor, a partir de 2015, sem perspectivas de crescimento, como se deu em anos anteriores a este estudo.

Tal panorama brota da crise atual no país, com menor crescimento das rendas familiares, encarecimento do crédito e ajuste do mercado imobiliário. Portanto, urge apontar num trabalho como o nosso, como as construtoras podem se sobressair à concorrência, buscando mecanismos de diferenciação e, essencialmente, a qualidade da prestação de seus serviços, gerando satisfação de seus clientes.

A gestão da qualidade, especificamente a ISO 9001, é um desses diferenciais exigidos pelo mercado no ramo da construção civil. No caso analisado, é elemento exigível até mesmo para obras públicas e de construção habitacional, tais como o programa do governo "Minha Casa, Minha Vida".

Conforme Paladini (2009, p. 05): "Nesse contexto, não há opção: tem sobrevivido e sobreviverá quem souber criar e continuar criando diferenciais. Dito de outro modo: o dilema não está entre produzir com qualidade ou não... é produzir com qualidade ou fechar".

O objetivo geral deste artigo, enfim, é o de analisar um episódio em particular: o processo de inserção da ISO 9001 e PBQP-H em uma construtora, cuja razão social foi ocultada a pedido da sua Direção. Vale dizer que pontuou a nossa escolha, o fato de que este é um segmento que influencia de modo significativo a economia de Frutal - MG. Ajusta-se a esta premissa, a ideia de que, para Severino (2007), este tipo de pesquisa estuda um episódio relacionado a um conjunto de outros semelhantes, e sua escolha se deve a uma suficiente representatividade, espécie de exemplificação para casos semelhantes. 
Utilizou-se por metodologia complementar, uma pesquisa bibliográfica exploratória para ampliar o conhecimento técnico, assim como o levantamento dos processos utilizados a partir de materiais já publicados. As informações do estudo são majoritariamente qualitativas, obtidas a partir de entrevistas e questionários estruturados como instrumentos para a coleta de dados primários.

Como parte do conjunto de procedimentos, foi realizada uma entrevista, em 03 de agosto de 2016, com a coordenadora de qualidade da empresa, a qual nos solicitou a ocultação de seu nome. Esta, por sua vez, é responsável pela implantação e manutenção do Sistema de Gestão da Qualidade - SGQ.

Foi aplicado ainda um questionário junto aos colaboradores da empresa em questão, no período de 25 de julho de 2016 a 05 de agosto de 2016, a fim de se obter um posicionamento dos mesmos quanto ao SGQ, além de suas motivações, dificuldades e benefícios ao participarem do processo.

\section{SISTEMA DE GESTÃO DA QUALIDADE NA CONSTRUÇÃO CIVIL}

O termo qualidade vem sendo cada vez mais debatido no mundo, tornando-se assunto de extrema relevância, despertando as empresas para a busca incessante da qualidade que, por sua vez, está ligada à evolução e ao aprimoramento de suas estruturas. As corporações, a seu turno, têm percebido que não basta ter excelência em determinado setor ou departamento, mas, sim, de maneira conjunta, verificando-se como diferentes esforços interagem para se atingir objetivos organizacionais.

O portal Venki (2015) destaca que a importância de se implantar um sistema de gestão de qualidade no setor da construção civil reside no fato de que isso possibilita a abertura de novos mercados e a ampliação dos existentes, aumentando as negociações das empresas com os clientes. Outro item de relevância, também, está na condição de que propiciam outros benefícios, como o aumento da produtividade dos colaboradores, a diminuição de desperdícios e custos, o controle eficiente dos processos e a melhoria da organização interna.

No mundo competitivo do século XXI, o grande desafio é conseguir convencer o cliente de que a empresa em que ele trabalha ou da qual é o proprietário é a melhor opção. Por isso, menor preço e uma proposta comercial bem apresentada são 
importantes, mas a certeza de que, durante a realização da obra, em todas as suas etapas, existirá qualidade, pode ser primordial. Todavia, para isso, a percepção da qualidade deve ocorrer desde o planejamento do método construtivo da obra, incluindo a escolha dos equipamentos que serão empregados, e nos serviços básicos de construção, conforme salientam Pinheiro e Crivelaro (2014, p. 79).

O setor da construção civil possui algumas características específicas, tais como heterogeneidade na prestação dos serviços, pouca qualificação e alta rotatividade da mão de obra, tradicionalismo, ou seja, pouca inovação tecnológica, ambiente de trabalho susceptível à ações do meio ambiente, falta de clareza e de definições objetivas nas especificações demandadas, mobilidade dos funcionários ao redor do bem fixo, mudança constante do local de trabalho dos operários e singularidade de todas obras realizadas (cf. PAIVA; SALGADO, 2003).

A adesão às normas ISO gera vantagens para as empresas, pois propicia à organização, produtividade e credibilidade, pontos facilmente identificados pelos clientes que buscam empresas que cumpram com tais requisitos. Um dos objetivos é a padronização do gerenciamento do sistema de qualidade, visando à sua unificação de forma universal. A função é a de promover a normalização de produtos, bens e serviços para que a qualidade seja permanentemente melhorada (PINHEIRO; CRIVELARO, 2014).

Com o objetivo de incentivar as empresas nacionais a aderirem à gestão da qualidade, e também com o intuito de inseri-las na competição com as empresas internacionais, o Governo Federal lançou, em 1991, o PBQP-H (Programa Brasileiro da Qualidade e Produtividade Habitacional). O foco era o de aplicar a qualidade na produção, reduzindo custos e aumentando a produtividade, a fim de se alcançar maior competitividade mediante à melhoria nos processos tecnológicos e de gestão (PINHEIRO; CRIVELARO, 2014).

Ainda segundo Pinheiro e Crivelaro (2014), a utilização de um sistema de gestão da qualidade nas construtoras tornou-se um requisito básico, pois, além de aumentar a eficiência organizacional, é uma exigência para a obtenção de financiamento habitacional.

Os autores reiteram que este tema ainda é recente no Brasil, porém, o setor de construção civil tem se conscientizado da importância de se documentar e utilizar um sistema de gestão de qualidade que ofereça as melhoras práticas, desde o projeto da obra à sua execução e manutenção. 
Não há dúvidas de que um sistema como este traz resultados positivos e contribui para a orientação do setor da construção civil, aumentando o equilíbrio das relações contratuais e a melhoraria da qualidade das obras. Além destas vantagens, os autores citam a utilização de um conjunto de boas práticas pelas empresas construtoras como contribuinte para a direção e a padronização das mesmas.

Afinal, já que uma grande parte do conhecimento deste setor é tácito e não explícito, ou seja, os profissionais não encontram documentos acerca do tema, mas aprendem informalmente, os sistemas compilam as boas práticas do processo de produção a partir de obras existentes e as documentam. Desta maneira, o conhecimento passa a ser difundido de maneira mais eficiente entre os profissionais da área.

Para as relações contratuais, as boas práticas são fundamentais, pois dão maior segurança ao contratante quanto à melhor qualidade das unidades e do atendimento aos principais requisitos de desempenho.

A implantação de um sistema de qualidade leva tempo e exige saber o papel da qualidade dentro do objetivo organizacional. Além disso, a fundação exige uma mudança geral, disseminando o conhecimento em todos os níveis. Para tanto, a qualidade necessita planejamento e exige que as pessoas envolvidas no sistema de implante da qualidade tenham conhecimentos técnicos (PINHEIRO; CRIVELARO, 2014).

\section{PBQP-H - PROGRAMA BRASILEIRO DA QUALIDADE E PRODUTIVIDADE DO HABITAT}

De acordo com o Ministério das Cidades (MCIDADES, 2015), o Programa Brasileiro da Qualidade e Produtividade do Habitat (PBQP-H) foi elaborado em 1991, e aplicado em 1998, pelo Governo Federal, por meio da Secretaria Especial de Desenvolvimento Urbano (SEDU).

Sua meta é aplicar a melhoria da qualidade do habitat e a modernização produtiva no setor da construção civil. Este programa foi criado principalmente para aumentar a competitividade do setor, promovendo a qualidade e a produtividade, além de apoiar o crescimento e modernização do país. Em longo prazo, o programa visa a reduzir o déficit habitacional, por meio do barateamento das construções e do aumento da qualidade, índices os quais podem ser alcançados quando o ambiente setorial se torna isonômico competitivamente. 
O escopo do programa se ampliou no ano 2000, quando começou a fazer parte do Plano Plurianual “Avança Brasil” (PPA), e incluíram-se nele áreas como transporte urbano, infraestrutura e saneamento, mudando a letra "H" da sigla PBQP-H, que antes significava "habitação", para habitat, ou seja, estendeu-se, com isso, a abrangência do programa à área de atuação (MCIDADES, 2015).

Na tabela 1, podem-se observar as evoluções do programa:

\section{Tabela 1 - Evolução das atualizações do PBQP-H}

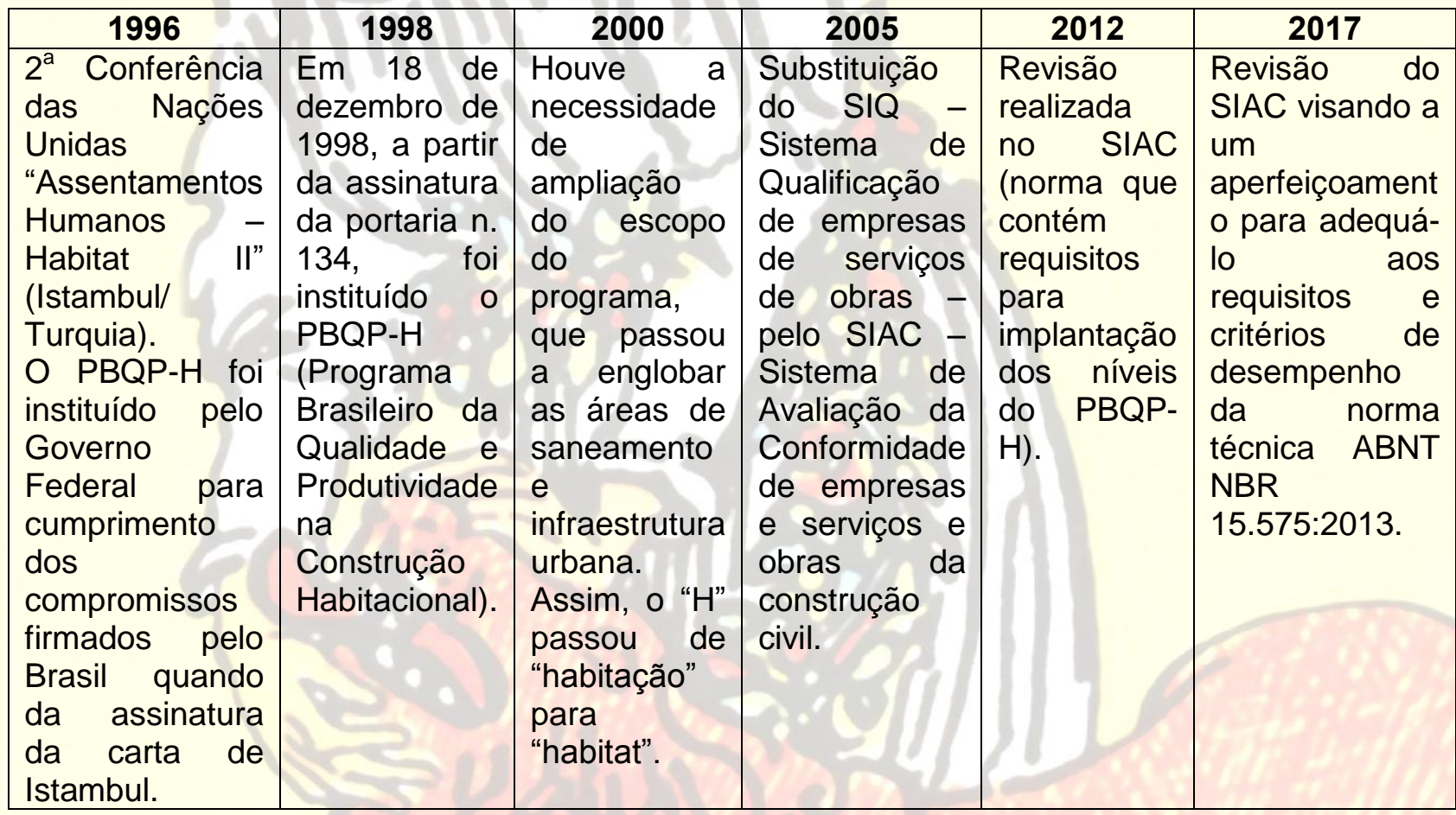

Fonte: elaborado pelas autoras, segundo dados do Ministério das Cidades, 2015

Pode-se observar que o Programa Brasileiro da Qualidade e Produtividade do Habitat (PBQP-H) é um instrumento do governo federal que tem como meta organizar o setor da construção civil em torno da melhoria da qualidade do habitat e da modernização produtiva a partir da qualificação de construtoras, mão-de-obra, fornecedores de materiais e serviços, dentre outros.

A adesão a ele não é obrigatória e é responsabilidade do gestor da organização decidir se quer ou não implementar e certificar o sistema de gestão da qualidade. Porém, agentes financiadores, como a Caixa Econômica Federal (CEF) e outras instituições financeiras, exigem a adesão. Além disso, o setor público, por meio do poder de compra, pressiona as empresas a buscarem a certificação. 
O PBQP-H (MCIDADES, 2015) afirma que a CEF tem sido a principal parceira do projeto, pois oferece financiamentos exclusivos para construtoras que são certificadas pelo programa. Dessa forma, a CEF atua como impulsionadora do aumento da qualidade, produtividade, competitividade e modernização produtiva.

Para o Ministério das Cidades (2015), o programa possui um elevado grau de aceitação, pois há aproximadamente 3000 construtoras ativas nos níveis de avaliação do Sistema de Avaliação da Conformidade de Empresas de Serviços e Obras da Construção Civil (SIAC/PBQP-H), demonstrando que este conquistou credibilidade junto ao segmento da construção civil.

A relação das empresas certificadas no Estado de Minas Gerais, até setembro de 2016, era de um total de 435 , com certificado SIAC, vigente em 2016, sendo que 378 pertenciam ao nível $A$, duas ao nível $B$, e 55 estavam no nível $D$ - o nível de ingresso/adesão no sistema.

A alteração para janeiro de 2017, segundo o Ministério das Cidades, seria necessário o alinhamento com a norma de desempenho NBR 15. 575: 2013.

O foco desta postura está nas especialidades técnicas, serviços especializados de execução e gerenciamento de obras, bem como nos empreendimentos e na elaboração de projetos. Deve-se considerar, ainda, que os Sistemas de Gestão da Qualidade - SGQs - atendam às suas exigências, compatíveis às da norma internacional ISO 9000. O novo SIAC trouxe em seu texto requisitos específicos para se comprovar o desempenho das construções executadas de acordo com a norma de desempenho.

\section{ISO 9001 INTERNATIONAL ORGANIZATION FOR STANDARDIZATION (ORGANIZAÇÃO INTERNACIONAL PARA PADRONIZAÇÃO)}

ISO é a sigla da International Organization for Standardization, a Organização Internacional de Padronização, de natureza não governamental e sediada em Genebra, Suíça. Foi fundada em 1947, contando, hoje, com 162 países membros e 3368 comitês técnicos (os TCs - ou technical committees).

A ISO 9000 é elaborada pelo comitê ISO/TC 176 e, desde seu lançamento, em 1987, suas normas foram evoluindo em estrutura, requisitos e enfoque. As três normas 
certificáveis da série ISO 9000:1987 tinham como grande enfoque a garantia da qualidade, tal qual a norma britânica BS-5750.

Em 1994, as três normas (9001, 9002 e 9003) continuavam com a abordagem de garantia da qualidade, porém, ampliou-se o conceito de Sistemas de Gestão da Qualidade (SGQs). Em 2000, a norma passou a ser a ISO 9001. Além da ênfase em sistemas de gestão da qualidade, ela trouxe a gestão por processos, deixando explícito o uso do PDCA (Plan, Do, Check, Act), o qual se define pelos oito princípios da qualidade.

A versão de 2008 não trouxe novidades significativas em relação à de 2000 , o que decepcionou muitos profissionais ávidos por alterações. Em 2015, chegou-se à versão ISO 9001:2015, desenvolvida sob a ótica do Anexo SL, de 2012, também conhecido como ISO Draft Guide 83, voltado a estruturas de alto nível, que define um padrão de requisitos normativos a serem utilizados para todas as normas ISO.

Assim, a ISO 9001:2015 era muito esperada e teve grande envolvimento mundial. Dentre suas inovações, a gestão de riscos, a inserção de novas terminologias, a redução de oito para sete princípios de qualidade foram os grandes destaques.

Isso possibilitou o exercício de uma reflexão sobre as práticas empresariais modernas e as mudanças do ambiente de negócios, proporcionando maior ênfase na obtenção da conformidade do produto, melhorando-se, assim, a compatibilidade com outras normas de sistemas de gestão. Por ser uma referência internacional amplamente reconhecida, tal norma busca identificar quais são os pontos mais críticos nas empresas e padronizar seus serviços.

O objetivo principal da norma em questão, como a própria ABNT (Associação Brasileira de Normas Técnicas, 2008) estabelece, é o de proporcionar a melhoria na gestão empresarial. Trata-se de uma ferramenta estratégica utilizada na maioria dos países, visando-se a estabelecer normas consistentes que aumentam a qualidade dos processos de gestão e intensificando a relação de confiança entre a empresa e seu cliente. O escopo vai além de se definir um padrão a ser seguido: ele exige acompanhamento, monitoramento e verificação da eficiência com o intuito de se incrementar o nível de qualidade de acordo com as exigências do mercado e de se facilitar o entendimento e a interpretação dos requisitos por parte das organizações e de seus sistemas de gerenciamento de qualidade.

Segundo Mello et al. (2009), a norma ISO 9001 estabelece requisitos que irão em conjunto formar um sistema de gestão da qualidade quando implementados internamente 
na organização. As empresas normalmente adotam-na para fins contratuais e/ou para certificação, e seu foco é a eficácia em satisfazer os requisitos de clientes atuais e potenciais.

De acordo com Vieira Filho (2012), a rápida difusão da norma ISO 9001 no mundo ocorreu devido à demanda de diversos países. Atualmente, as importações só ocorrem através de organizações certificadas por essa norma, e isso ocorre porque os países envolvidos sabem que a qualidade do atendimento e do produto/serviço adquirido será bem maior do que se importassem de organizações que não possuam nenhum tipo de sistema de gestão da qualidade implementado.

De acordo com Vieira Filho (2012) e Marshall Junior et al. (2010), os clientes potenciais normalmente exigem a certificação do sistema de gestão qualidade ISO 9001 da organização vendedora. Essa prática se dá em virtude da confiança, entre as partes envolvidas, de que os requisitos combinados serão atingidos e de que o sistema de gestão da qualidade será aprimorado continuamente.

Os requisitos especificados pelo sistema de gestão da qualidade ISO 9001 são aplicados na organização quando ela precisa comprovar sua capacidade de fornecer produtos que irão ao encontro das expectativas do cliente e dos requisitos regulamentares exigidos. A intenção aqui é o de aumentar a satisfação dos clientes, incluindo-se a melhoria continuada no sistema e garantindo-se a conformidade do produto ou serviço com os requisitos regulamentares (VIEIRA FILHO, 2012).

Poldermans (2015), responsável pela ISO 9001 do organismo certificador DVN GL, resume o fator de maior importância decorrente desta revisão:

Como todas as novas normas de sistema de gestão ISO, a ISO 9001 está agora alinhada com a chamada estrutura de alto nível. Isso significa que todas as novas normas de sistema de gestão ISO serão alinhadas com a dos requisitos comuns, o que tornará mais fácil para as organizações a implementarem daqui para frente (POLDERMANS, 2015).

Para Prado Filho (2009), os requisitos demandados pela norma ajudam no aumento da capacitação da equipe, no aperfeiçoamento dos processos da empresa, no controle do ambiente de trabalho, na constatação da satisfação dos consumidores, fornecedores e da equipe e no aumento da produtividade e eficácia da empresa. As organizações e pessoas que almejam a qualidade precisam ter uma visão positiva sobre a mudança, pois qualquer tipo de melhoria, até mesmo pequena, é bem-vinda. As 
inovações devem ser conhecidas pelas empresas, testadas e aplicadas quando possível. Para se implementar um sistema de gestão da qualidade, a organização deve ter consciência de que o caminho que segue deve ser reavaliado.

\section{CERTIFICAÇÃO, MANUTENÇÃO, BENEFíCIOS E DIFICULDADES DO SISTEMA DE GESTÃO DA QUALIDADE}

De acordo com Marshall Junior et al. (2010), existem três motivos que podem levar uma organização a implementar um SGQ, sejam elas: conscientização da alta administração; demandas externas; e, por incrível que possa parecer, puro modismo.

Quando o motivo que levaria a uma implantação de um SGQ eficaz é a conscientização por parte da alta administração, isso, provavelmente, se deve ao fato de que a cúpula está envolvida totalmente nos processos da organização. Isto é, todos os departamentos da organização se uniriam para o sucesso de um objetivo em comum, que resultaria em vantagem competitiva para si.

O processo tende a ser difícil, podendo até mesmo ser traumático para a organização quando ela implementa um SGQ devido às exigências externas, tal o que acontecem em função da entrada da empresa em processos de licitação, em novos mercados ou quando sofre pressão de clientes.

Ainda, de acordo com Marshall Junior et al. (2010), o processo de certificação pode ser definido como as ações executadas por um órgão autônomo com o qual não se tem qualquer tipo de relação comercial. A finalidade, neste caso, é a de se comprovar publicamente o ato e, por escrito, que um produto, serviço ou processo está compatível com os requisitos exigidos, sendo que estes podem ser nacionais, estrangeiros ou internacionais.

Carpinetti, Miguel e Gerolamo (2011) afirmam que a certificação do sistema de gestão da qualidade ISO 9001 é um procedimento pelo qual o órgão certificador analisa o SGQ da organização interessada em conseguir um certificado, atestando se ele condiz com os requisitos estabelecidos pela ISO 9001.

Numa definição corroborada por Zacharias (2001), se entende que a empresa consegue sua certificação quando um organismo independente julga que os processos e o produto final estão em conformidade com os requisitos da norma. 
Devido às normas ISO serem de caráter voluntário, elas não têm como função controlar a utilização das mesmas pelas empresas, que devem ser compreendidas somente entre o fornecedor e seu cliente. Por essa razão, a ISO, apesar de ter suas normas bem aceitas, não confere nenhum certificado, nem em seu nome.

Empresas especializadas em auditoria não possuem qualquer concessão da ISO para executá-lo. Essas surgiram para exercer a função que a ISO não realiza, e conferem certificados por meio de auditorias externas às empresas que estão em conformidade com a ISO 9001 (MAXIMIANO, 2005).

Segundo Carpinetti, Miguel e Gerolamo (2011), as empresas especializadas em auditoria ou órgãos certificadores são chamadas de "auditoria de terceira parte". Por assim dizer, o termo "Auditoria" se emprega, devido ao caráter oficial da avaliação e, a expressão "terceira parte", porque aquela não é feita pela própria empresa auditada (a "primeira parte") ou por um cliente da empresa (uma "segunda parte"), mas, sim, por um órgão independente.

No Brasil, o órgão reconhecido internacionalmente e que realiza o credenciamento de organismos certificadores que emitem o certificado ISO é o Instituto Nacional de Metrologia, Normalização e Qualidade Industrial (INMETRO).

O certificado ISO 9001 tem validade de 03 anos, com manutenções anuais, necessitando de renovação após esse período. Recomenda-se a cada semestre ou mesmo anualmente realizar uma auditoria interna, a fim de se observar se o sistema de gestão continua atendendo aos requisitos da norma. Se a empresa deixar de cumprir com algum requisito, seu certificado não será mantido (CARPINETTI; MIGUEL; GEROLAMO, 2011).

Para se obter a certificação, Pinheiro e Crivelaro (2014) e Zacharias (2001) sugerem alguns passos ou procedimentos: comprometimento da alta direção; indicação formal do coordenador da qualidade; planejamento e padronização; palestra sobre qualidade/ISO 9001 para todos os colaboradores; treinamento; realização de auditorias internas; escolha da entidade certificadora; auditoria pré-certificação; auditoria de certificação; e, enfim, a implantação das ações corretivas para as não-conformidades evidenciadas durante o processo.

Prado Filho (2009) afirma que a certificação traz como vantagens o aumento da satisfação e da confiança dos consumidores, a redução dos custos internos, o aumento da produtividade, a melhoria da imagem e dos processos de maneira continuada, bem 
como o aumento da facilidade de acesso a novos mercados. Podemos acrescentar a estas vantagens o marketing, ou seja, a vantagem publicitária obtida com a divulgação da empresa a ser certificada, demonstrando aos fornecedores e clientes seu compromisso com a qualidade.

Segundo Rodrigues (2008), o gestor que pretende certificar sua empresa, por exigência ou não do mercado, não deve ver isso apenas como uma forma de aumentar os lucros da empresa. Esta pode até ser uma consequência da certificação, pois a credibilidade aumentará. Porém, o benefício real ocorre com a melhoria dos processos e com a diminuição da rotatividade de funcionários, retrabalhos, dentre outros aspectos. Entretanto, o que normalmente ocorre nestes processos, muitas vezes, é que esses ganhos subjetivos não são considerados na conta balanço, o que é um erro.

Em relação aos benefícios internos, os autores citam como mais importantes: aumento da satisfação dos clientes; um fornecedor preferencial para empresas certificadas (ZACHARIAS, 2001); redução do custo de retrabalhos, desperdícios e reposições; o aumento da competitividade e do lucro (MARSHALL JUNIOR et al., 2010; Zacharias, 2001); diminuição de bens e serviços não conformes; maior sustentação em disputas judiciais; melhoria da imagem da marca e o aumento de sua reputação; melhoria no relacionamento comercial e técnico com os clientes (MARSHALL JUNIOR et al., 2010); diminuição do custo operacional e dos ciclos de tempo de produção e/ou realização de atividades por meio do uso efetivo dos recursos; aumento da flexibilização e da rapidez de resposta às oportunidades oferecidas pelo mercado - o que resulta em maior participação no mercado nacional e internacional, com uma facilidade de exportação devido ao atendimento às exigências internacionais; maior integração entre os processos e departamentos da empresa, melhorando a comunicação interna entre os diferentes níveis da organização; cultura da qualidade, com melhor desempenho organizacional mediante a promoção do treinamento, da qualificação e da certificação do pessoal, o que resulta em uma melhor compreensão dos objetivos e metas bem como das responsabilidades dos funcionários da empresa, o que eleva a motivação (MARSHALL JUNIOR et al., 2010; PINHEIRO e CRIVELARO, 2014).

Dando continuidade à intensa lista de aspectos positivos, temos ainda um aumento da facilidade na avaliação das melhorias e quantificação dos bens e serviços, resultando em acréscimo da capacidade de se tomar decisões mais eficazes; maior integração e adaptação dos processos que melhor contribuem para a obtenção dos resultados 
desejados (PINHEIRO e CRIVELARO, 2014); clima organizacional voltado à melhoria, com aumento da capacidade de se identificar oportunidades de melhorias, dirigidas e priorizadas (PINHEIRO e CRIVELARO, 2014; ZACHARIAS, 2001).

Os principais benefícios obtidos pela sociedade e pelos clientes são: diminuição do desperdício e da poluição; melhoria no relacionamento técnico e comercial do cliente com o fornecedor; maior proteção para os clientes; aumento do desenvolvimento tecnológico da empresa; maior segurança, confiabilidade e disponibilidade dos bens e serviços comprados; melhor atendimento da empresa em caso de reclamações dos clientes; redução do custo de inspeção e recebimento do produto, já que os fornecedores certificados irão cumprir o escopo, desobrigando o cliente de inspecioná-lo; aumento efetivo de satisfação dos clientes (MARSHALL JUNIOR et al., 2010; ZACHARIAS, 2001).

A motivação para as empresas buscarem uma certificação habitualmente se dá por motivos externos, vinculados a uma dificuldade maior de se alcançar os benefícios da ISO. Neste caso, é grande o empenho na implementação da norma, já que as empresas precisam também permanecer focadas em seu ramo de negócio. Ainda assim, tais empresas não alcançarão muitos benefícios devido ao estreito foco na importância de uma tal implementação, ao contrário de empresas que veem na certificação uma possibilidade de melhorarem a qualidade de seus bens e serviços. Estas últimas costumam obter mais benefícios com este processo (SAMPAIO et al., 2009, apud RIBEIRO, 2012).

Todas as organizações, quando vão passar por um processo de transição, devem realizar mudanças no estilo de gestão, na aplicação de ferramentas gerenciais ou operacionais, na implementação de sistemas de gestão, etc. Por isso, enfrentam dificuldades que vão desde o custo da operação até barreiras culturais. Elencamos algumas identificadas por este estudo a partir do investimento que se precisa para a implantação da ISO 9001, e que representam dificuldades para as empresas. De imediato, são necessários recursos financeiros para consultoria, treinamento e para a própria certificação, o que, consequentemente, requer tempo dos colaboradores, além de investimentos em hardware, software e humanware ${ }^{6}$ (ZACHARIAS, 2001).

Alguns autores enfatizam como dificuldades e pontos negativos relativos à certificação, o excesso de documentação que o sistema exige, o que resulta em mais custos e maior dedicação do tempo da equipe. Também reiteram a falta de

\footnotetext{
${ }^{6}$ Modelo de gerenciamento do fator humano, desenhado para oferecer ferramentas de prevenção, diagnóstico e manejo de conflitos ao longo do ciclo de vida de um projeto.
} 
compatibilidade da norma para com outros sistemas de gestão. $\mathrm{Na}$ realidade, tais afirmações são consideradas corretas, até a versão de 2008, pois, na ISO 9001:2015, esses problemas foram sanados. Não há mais exigência em se documentar o sistema e também foram feitas adaptações, a fim de que a norma se torne compatível com outros sistemas de gestão ISO.

Vale destacar a presença de algumas dificuldades que ainda persistem no processo: resistência à mudança em todos os níveis da organização (inclusive na alta direção); problemas de comunicação entre os colaboradores; falta de tempo para a devida implantação; custo com recursos materiais (hardware, software, mobília etc.); custo e tempo com recursos humanos (palestras, treinamentos, contratação de coordenador da qualidade e/ou consultores etc.); e, um significativo tempo gasto pela alta administração no envolvimento e acompanhamento da implementação e manutenção do SGQ.

Entretanto, alguns consultores afirmam que a probabilidade de recuperação do investimento em qualidade gira em torno de três anos depois da certificação e consideram a falta de envolvimento e participação da alta administração como a maior dificuldade para o estabelecimento do SGQ (PINTO E SOARES; GOTZAMANI, 2010, apud RIBEIRO, 2012).

Ujihara, Cardoso e Chavez (2006) ressaltam alguns fatores relevantes apontados pelo CB-25 da ABNT (Associação Brasileira de Normas Técnicas), tais como: dificuldades de implantação e certificação do SGQ, devido à mudança de cultura (25\%); a resistência dos funcionários (21\%); a dificuldade para com a capacitação dos funcionários (13\%); a burocracia (8\%); a variação quanto à interpretação das normas (8\%); e, a própria adequação à norma (3\%). Algumas destas questões são pontuais em cada empresa. É importante não generalizar, uma vez que estas, por outro lado, também são demandas intrínsecas ao processo de certificação, e que acontecem na maioria das empresas identificadas pelos autores utilizados nesta revisão bibliográfica.

Vale destacar, neste sentido, que essas barreiras podem ser amenizadas com um monitoramento efetivo dos processos e com uma boa gestão dos ciclos de manutenção. A certificação é uma atividade dinâmica, pois, de tempos em tempos, é necessário que se faça a revisão, que costuma incluir requisitos novos. E a empresa precisa sempre se adaptar a eles, melhorando seu SGQ, a fim de se manter certificada (MARSHALL JUNIOR et al., 2010). 
Marshall Junior et al. (2010) e Vieira Filho (2012) frisam que a adoção do ciclo $\mathrm{PDCA}^{7}$, como o representante mais conhecido do melhoramento continuado, é um aliado ao planejamento da empresa. O ciclo PDCA é uma tecnologia gerencial de tomada de decisões. Suas quatro etapas, quando realizadas ciclicamente e sem interrupções, promovem a melhoria contínua da organização, tão importante para o sucesso da empresa. A partir de sua adoção é possível assegurar que, devido à melhoria contínua, os objetivos podem ser alcançados. Em caso contrário, volta-se à primeira etapa (a do planejamento) e definem-se novas metas, desafios, procedimentos, métodos etc. Trata-se de uma ferramenta ideal a ser utilizada para se verificar, nas auditorias internas, se o sistema está em conformidade às normas ou se precisa de adequações. Desta maneira, a empresa consegue fazer a manutenção de seu sistema de forma eficaz.

\section{ANÁLISE E TRATAMENTO DOS DADOS}

O estudo de caso foi realizado em uma empresa do ramo da construção civil, a qual foi escolhida por possuir certificação ISO 9001 e, também, por atender aos requisitos do SIAC (Serviços e Obras da Construção Civil) PBQP-H.

No período da pesquisa, a corporação ainda não havia passado pela transição da versão 2008 da norma ISO 9001 para a versão 2015, nem pelo PBQP-H/2017.

Foram duas as etapas de estudo: a primeira, entrevista realizada com a coordenadora de qualidade, o que possibilitou definir o quadro de implementação, obtenção, manutenção da certificação, melhoria contínua do $S G Q$ e o processo que a construtora passaria para se adequar à nova versão da ISO.

A segunda etapa, complementar à entrevista, foi a realização de um inquérito por meio de questionários aplicados aos colaboradores da construtora, com o intuito de verificar se as afirmações de cada entrevistado correspondiam à visão dos colaboradores.

A empresa em questão tem mais de 37 anos de atuação na construção de unidades habitacionais, comerciais e industriais, e executa obras públicas e privadas, atualmente edificadas dentro dos mais altos padrões de qualidade assegurados pelo SGQ.

\footnotetext{
${ }^{7}$ Também chamado de "Ciclo de Deming" ou "Ciclo de Shewhart", é sigla das expressões: Plan, Do, Check, e Action (Planejar, Fazer, Verificar e Agir).
} 
O tipo de estrutura organizacional é a hierarquizada, que emprega a departamentalização por funções, com ênfase na unidade de comando vertical e na comunicação horizontal. A implantação do SGQ se apresenta como uma estratégia obrigatória para a manutenção da capacidade competitiva, uma vez que a certificação para o ramo de atuação se tornou determinante em um de seus principais mercados.

Durante a realização de entrevistas, os que não souberam responder, em sua maioria, trabalhavam havia menos de 03 anos na empresa ou faziam parte da execução das obras, função em que normalmente há uma grande rotatividade.

Foram feitas perguntas relacionadas à percepção dos colaboradores acerca da certificação ISO 9001, a fim de se diagnosticar o quão estão integrados e são conhecedores da empresa na qual trabalham. O resultado diagnosticado foi positivo, pois $89 \%$ concordaram que a empresa certificada estava mais comprometida com o funcionário; $70 \%$ afirmaram possuir algum conhecimento sobre o conteúdo da norma ISO 9001; 96\% e concordaram que os conhecimentos adquiridos na empresa sobre o SGQ contribuiriam para seu desenvolvimento profissional e pessoal. Verificou-se também a percepção do antes e do depois da certificação: cerca de $48 \%$ dos funcionários questionados já estavam trabalhando na empresa quando foi feita a implementação do SGQ. Para a maioria deles, isso facilitou o trabalho (88\%) e aumentou a autonomia $(67 \%)$.

Em relação à manutenção da certificação, o coordenador de qualidade respondeu em conformidade ao que se verificou no referencial teórico empregado neste trabalho: a empresa se utiliza do PDCA, ferramenta de melhoria contínua, para manter e checar o cumprimento do SGQ. Além disso, são realizadas auditorias internas que possibilitam o acompanhamento constante e a correção de erros quando necessário. O coordenador ainda apontou que, mediante o monitoramento, houve aumento da qualidade do produto e dos serviços prestados, redução de retrabalhos e mais satisfação dos clientes internos e externos.

Os funcionários entrevistados citaram ainda diversos motivos que justificavam a contribuição da ISO para o desenvolvimento organizacional, profissional e pessoal. Alguns deles foram mencionados pela maioria, tais como conhecimento/aprendizado, como proceder no trabalho/rotina da obra, organização, clientes satisfeitos, trabalhar com produtos de qualidade, cultura de melhoria contínua, aprender sobre coleta seletiva e primeiros socorros, comprometimento, cultura de responsabilidade ambiental e social, 
treinamentos e melhoria na comunicação e, ainda, vários disseram que percebiam a diferença de se trabalhar em uma empresa certificada no mercado, tornando-se mais valorizados pela concorrência.

Os resultados do estudo focaram principalmente nos benefícios e dificuldades da certificação ISO 9001. Ainda dentro do contexto da certificação, buscou-se conhecer as motivações da empresa e se ter uma visão geral dos colaboradores sobre trabalharem em uma companhia certificada. Comparando-se os dados obtidos da entrevista realizada com a coordenadora de qualidade com os dados oriundos dos questionários aplicados aos colaboradores, verifica-se que as motivações internas e externas são as mesmas citadas, mudando-se apenas as palavras utilizadas. Então, é possível notar que a empresa não teve razões apenas internas ou apenas externas, mas ambas, e todos as conheciam.

Relacionando-se as motivações com os benefícios, Heras, Dick e Casadesús (2002) e Sampaio et al. (2009) afirmaram que há uma relação entre ambos no sentido de que, se as motivações forem internas, os benefícios serão internos. O contrário também se daria: se as motivações fossem externas, os benefícios seriam externos. Desta maneira, como a empresa teve motivações tanto internas quanto externas, segundo a visão tanto dos colaboradores e do coordenador de qualidade, também houve benefícios internos e externos.

Neste sentido, apenas 02 benefícios tiveram uma discordância relevante (acima dos 50\%): motivação e melhoria na comunicação interna. Ou seja, trabalhar em uma empresa certificada não motiva os funcionários e não teve uma expressiva mudança na comunicação interna mediante a certificação. A maior concordância se deu em relação aos treinamentos: os funcionários afirmaram terem aprendido novas técnicas e métodos de trabalho.

Os benefícios internos citados pelo coordenador de qualidade, tais como padronização e redução de erros e retrabalhos, e os externos, como marketing e permanência da empresa no mercado, vão ao encontro dos citados no referencial teórico por Prado Filho (2009), Rodrigues (2008), Heras, Dick e Casadesús (2002), Marshall Júnior et al. (2010), Pinheiro e Crivelaro (2014) e Zacharias (2001).

O benefício da diminuição da rotatividade dos funcionários defendido por Rodrigues (2008) não foi considerado pelo coordenador de qualidade e isso se deveu ao setor de construção civil possuir uma alta rotatividade, como citado no referencial teórico por Paiva e Salgado (2003). 
Em relação os principais problemas, o coordenador de qualidade destacou: envolvimento da gestão do topo, também indicado por Sampaio et al (2009); resistência à mudança, conforme apontado por Gotzamani (2010); e aumento do custo devido à preparação e implementação do $S G Q$, o que havia sido realçado em trabalho de Zacharias (2011). O excesso da documentação e a incompatibilidade da norma para com outros processos foram citados também no processo de implantação da versão 2008 , diferentemente da nova, a ser implantada.

A percepção dos colaboradores sobre algumas dificuldades pelas quais a empresa passou até se adaptar com o SGQ não correspondeu à visão do departamento de qualidade. São elas: descomprometimento da direção (90\% discordaram ser um fator de dificuldade) e o excesso de documentação/burocracia (56\% discordaram ser um fator de dificuldade). Como visto nos benefícios, a certificação não gerou motivação $(55 \%)$, porém, também não foi um fator de desmotivação para os funcionários, já que $90 \%$ discordaram sobre este item ser uma dificuldade. Todas as dificuldades apresentadas obtiveram uma discordância maior do que a concordância, portanto, em geral, os colaboradores não sentiram dificuldades na formalização do SGQ, nem em se trabalhar em uma empresa certificada.

Quanto à discordância dos colaboradores em relação ao comprometimento da direção na certificação da qualidade, isso se deve possivelmente ao fato de a alta administração estar mais próxima da coordenação do que do operacional, minimizando sua percepção quanto a este requisito e apenas concordando em relação aos benefícios que a ISO 9001 traz para a empresa e sua importância para o desenvolvimento e boa gestão empresarial.

Atualmente, a empresa estudada se encontra em uma fase bastante consolidada, com seus processos mais esclarecidos, proporcionando vantagens competitivas no mercado e gerando bons resultados. Isso demonstra um bom caminho para que outras empresas sigam o mesmo rumo, buscando-se, sempre, a excelência em processos e serviços. Tal implementação também representa um forte instrumento quando da definição de metas e objetivos estratégicos, fortalecendo-se o espírito de trabalho em equipe e a superação das dificuldades. 


\section{CONSIDERAÇÕES FINAIS}

A satisfação de cada cliente, o planejamento do empreendimento, a definição dos projetos, a execução das obras, a constante observação sobre os cronogramas, as exigências para com a qualidade dos materiais, da mão-de-obra e a precisão de cada etapa da edificação são aspectos de constante preocupação por parte da empresa.

Esse conjunto de cuidados tem grande influência sobre o nível de satisfação da organização e de seus clientes. São atitudes que caracterizam processos com requisitos transparentes, comunicação clara e eficaz dos objetivos da empresa pertinentes aos resultados esperados, e programas de treinamento, visando a potencializar os conhecimentos e o aperfeiçoamento contínuo dos serviços prestados.

De modo geral, ao se comparar os motivos dados pelo coordenador de qualidade da empresa com os fornecidos pelos colaboradores, percebemos que são similares. Portanto, a maioria dos funcionários tinha consciência do motivo de a construtora ter obtido a certificação ISO 9001 (43,49\% não souberam responder a esta pergunta). resultado foi positivo, pois os colaboradores entenderam melhor os processos internos da companhia e não ficaram receosos quanto a trabalhar em uma empresa certificada, já que compreendiam a importância de tal certificação.

$\mathrm{Na}$ bibliografia pesquisada, os dados sobre os benefícios sentidos pelos colaboradores, ao fazerem parte de uma empresa certificada, foram pouco abordados. Por isso, fez-se necessário aprofundar este tema na pesquisa, pois se tratam de um dos fatores que colaboram para o sucesso da empresa.

Os colaboradores são o espelho das empresas e eles devem saber os papeis que desempenham nela para que atendam bem os clientes e estes fiquem satisfeitos. Neste contexto, está inserida a cultura da empresa, que pode influenciar positiva ou negativamente o comportamento dos funcionários e, consequentemente, a imagem externa da companhia. Conhecer a ISO 9001 e sua importância para a organização é essencial para os funcionários, que se sentirão integrados e promoverão uma imagem positiva dos produtos e serviços da organização, aumentando o seu valor no mercado.

Quando a empresa conhece as dificuldades que podem encontrar na certificação, ela pode fazer um planejamento de maneira que aquelas sejam evitadas ou resolvidas rapidamente, a fim de se obter um maior aproveitamento da implementação da ISO 9001. 
A percepção dos benefícios fará com que as empresas optem pela certificação de maneira consciente e rápida.

Presentemente, há uma busca cada vez maior dentro das organizações, por intermédio de seus gestores, pela melhoria da gestão organizacional, requisitando mecanismos para controlar e medir seus processos, reduzindo-se, assim, o desperdício e maximizando resultados, o que aumentará a satisfação de seus clientes e colaboradores.

Percebe-se que o SGQ é um processo que contribui com o controle e a padronização dos procedimentos e, também, permite a medição da eficácia das ações tomadas, com foco na satisfação do cliente e na busca da melhoria contínua dos processos.

Há que se destacar também que um SGQ, depois de implantado, pode influenciar positivamente a organização, mudando atitudes, aumentando o comprometimento, bem como o envolvimento de todas as partes interessadas. Além disso, a imagem e a credibilidade que a certificação proporciona à empresa são grandes diferenciais frente ao mercado, especialmente com vistas à competitividade e à captação de novos clientes. A empresa também considera sua satisfação em manter o certificado, sempre passando pelos processos de manutenção e recertificação.

Conclui-se, então, que a certificação do SGQ declara o compromisso da empresa com a qualidade de seu produto ou serviço, tendo como objetivo a satisfação do cliente. Além disso, é uma ferramenta de disseminação que irá divulgar uma imagem positiva da empresa no mercado em que atua, sendo bem vista por acionistas, clientes e, no caso da construção civil, também por órgãos de financiamentos, que reconhecem a padronização de processos na gestão da qualidade por meio de resultados positivos, tanto internos quanto externos.

A proposta deste artigo foi o de despertar o interesse pela busca por prestação de serviços com qualidade para a satisfação do cliente. Recomenda-se que se prossigam pesquisas como esta, face às possibilidades de análise da evolução econômico-financeira que o mercado sempre requisita.

Em suma, foi mediante o estudo da implantação de um sistema de gestão da qualidade em construtoras, que nos foi viável mensurar a realidade da redução de custos operacionais, avaliando-se o desempenho e a lucratividade, e, ainda, oferecendo-se um estudo direcionado em relação ao custo-benefício da certificação PBQP-H adotado por tais construtoras. 


\section{REFERÊNCIAS}

ASSOCIAÇÃO BRASILEIRA DE NORMAS TÉCNICAS (ABNT). NBR ISO 9000:2005. Sistema de Gestão da Qualidade. Fundamentos e Vocabulário. Rio de Janeiro, 2005.

de Gestão da Qualidade. Requisitos. Rio de Janeiro, 2008.

NBR ISO 9001:2008. Sistema

NBR ISO 9001:2015. Sistema

de Gestão da Qualidade. Requisitos. Rio de Janeiro, 2015.

CARPINETTI, Luiz Cesar Ribeiro et al. Gestão da Qualidade ISO 9001:2008. Princípios e Requisitos. São Paulo: Atlas, 2011.

FONSECA, Regina Célia Veiga da. Metodologia do Trabalho Científico. Curitiba: Jesde: Brasil, 2009.

GIL, Antonio Carlos. Como Elaborar Projetos de Pesquisa. São Paulo: Atlas, 2010.

HERAS, Iñaki et al. ISO 9000 registration's impact on sales and profitability. In: Int J Qual \& Reliability Mgmt, v. 19, n. 6, p. 774-791, set. 2002. Disponível em: http://www.sc.ehu.es/oewhesai/p774.pdf. Acesso em: 13 jul. 2015.

INSTITUTO NACIONAL DE METROLOGIA, QUALIDADE E TECNOLOGIA (INMETRO). Disponível em: http://certifiq.inmetro.gov.br/Consulta/CertificadosConce-didosUF. Acesso em: 23 set. 2019.

JANUZZI, Ulysses Amarildo; VERCESI, Cristiane. Sistema de gestão da qualidade na construção civil: um estudo a partir da experiência do PBQP-H junto às empresas construtoras da cidade de Londrina. In: Revista Gestão Industrial, v. 6, n. 3, p. 136-160, 20 out. 2010. Universidade Tecnológica Federal do Paraná (UTFPR). Disponível em: https://periodicos.utfpr.edu.br/revistagi/article/viewFile/584/536. Acesso em: 15 set. 2015.

MARCONI, Marina de Andrade; LAKATOS, Eva Maria. Fundamentos de Metodologia Científica. São Paulo: Atlas, 2003.

MARSHALL JUNIOR, Isnard et al. Gestão da Qualidade. Rio de Janeiro: FGV, 2010.

MAXIMIANO, Antonio Cesar Amaru. Teoria Geral da Administração: da revolução urbana à revolução digital. São Paulo: Atlas, 2005.

MINISTÉRIO DAS CIDADES (MCidades). Disponível em: http://pbqp-h.cidades.gov.br/. Acesso em: 10 set. 2015.

MELLO, Carlos Henrique Pereira et al. ISO 9001:2008: Sistema de Gestão da Qualidade para Operações de Produção e Serviços. São Paulo: Atlas, 2009.

OLIVEIRA, K. G. S. Análise das Mudanças do Novo SIAC (Pbqp-H) e os possíveis impactos no setor da construção civil. TCC no Curso de Engenharia Civil da UFPB, João Pessoa, 2017. Disponível em: https://security.ufpb.br/ccec/contents/documentos/tccs/2016.2/analisedas-mudancas-do-novo-siac-pbqp-h-e-os-possiveis-impactos-no-setor-da-construcao-

civil.pdf. Acesso em: 10 set. 2019.

PAIVA, Mônica Souto de; SALGADO, Mônica Santos. Treinamento das equipes de obras para implantação de sistemas da qualidade. Disponível em: 
http://www.abepro.org.br/biblioteca/ENEGEP2003 TR0208 0179.pdf. Acesso em: 10 set. 2015.

PALADINI, Edson Pacheco. Gestão Estratégica da Qualidade - Princípios, Métodos e Processos. São Paulo: Atlas, 2009.

PINHEIRO, Antonio Carlos da Fonseca Bragança; CRIVELARO, Marcos. Qualidade na Construção Civil. São Paulo: Érica, 2014.

POLDERMANS, Bastiaan. Disponível em: http://www.dnvba.com/br/lnformacoes/noticias\%20press-releases/Pages/ISO-9001-2015.aspxpress-releases/Pages/ISO-9001-2015.aspx.

Acesso em: 17 de mai. 2015.

PORTAL TEMPLUM. Disponível em: http://certificacaoiso.com.br/passo-a-passocertificacao-http://certificacaoiso.com.br/passo-a-passo-certificacao-\%20iso-9001/. Acesso em: 10 de mai. 2016.

Disponível em: http://certificacaoiso.com.br/iso9001/manutencao-http://certificacaoiso.com.br/iso-9001/manutencao-\%20sistema-gestaoqualidade. Acesso em: 17 jun. 2016.

PORTAL VENKI. Disponível em: http://www.venki.com.br/blog/gestao-da-qualidade-na\%20construcao-civil/construcao-civil/. Acesso em: 20 jun. 2015.

PRADO FILHO, Hayrton Rodrigues do. Qualidade sem medo. Campinas: Epse, 2009.

RIBEIRO, Sandra Isabel; PEREIRA, Maximiano Coelho. Os benefícios e as dificuldades na certificação da qualidade: Norma NP EN ISO 9001:2008. 2012. Dissertação (Mestrado), Curso de Administração, Instituto Superior de Contabilidade e Administração do Porto: São Mamede de Infesta, 2012.

RODRIGUES, Ronaldo Costa. Vale a pena ter ISO 9001? / 2008.

SANTOS, Glauber Eduardo de Oliveira. Cálculo amostral: calculadora on-line. Disponível em: http://www.calculoamostral.vai.la/. Acesso em: 16 set. 2016.

SEVERINO, Antônio Joaquim. Metodologia do Trabalho Científico. São Paulo: Cortez, 2007.

SINDICATO DA INDÚSTRIA DA CONSTRUÇÃO DO ESTADO DE MINAS GERAIS (SINDUSCON). Disponível em: http://www.sinduscon-mg.org.br/. Acesso em: 09 de abr. 2015.

SOUZA, Roberto de; ABIKO, Alex. Metodologia para Desenvolvimento e Implementação de Sistemas de Gestão da Qualidade em Empresas Construtoras de Pequeno e Médio Porte. In: Boletim Técnico da Escola Politécnica da USP, São Paulo, p. 5-5, 1997. Disponível em: http://www.planoauditoria.com.br/site/download/120908 gestaoqualidade poli usp btp cc190_1.pdf. Acesso em: 08 jun. 2016.

TOLEDO, José Carlos de; MARTINS, Roberto Antônio. A Proposta de Modelo para a Elaboração de Programas de Gestão para a Qualidade Total. In: Revista de Administração, FEA-USP, v. 33, n. 2, p. 52-59, 1998.

VIEIRA FILHO, Geraldo. Gestão da Qualidade Total: uma abordagem prática. Campinas: Alínea, 2012.

ZACHARIAS, Oceano. ISO 9000:2000. Conhecendo e implantando: uma ferramenta de gestão empresarial. São Paulo: O. J. Zacharias, 2001. 